\title{
PCR past, present and future
}

\section{Hanliang Zhu1 iD, Haoqing Zhang1 ${ }^{1}$, Ying Xu1 , Soňa Laššáková2 ${ }^{1}$ Marie Korabečná2 iD \& Pavel Neužil*,1,3,4 iD}

${ }^{1}$ Department of Microsystem Engineering, School of Mechanical Engineering, Northwestern Polytechnical University, Xi'an, Shaanxi 710072, PR China; ${ }^{2}$ Institute of Biology \& Medical Genetics, First Faculty of Medicine, Charles University \& General University Hospital in Prague, Purkyně Institute, Albertov 4, Praha 2 128 00, Czech Republic; ${ }^{3}$ Brno University of Technology, Central European Institute of Technology, Purkyňova 123, 61200 Brno, Czech Republic; ${ }^{4}$ Brno University of Technology, Faculty of Electrical Engineering and Communications, Technická 3058/10, 61600 Brno, Czech Republic; *Author for correspondence: pavel.neuzil@nwpu.edu.cn

BioTechniques 69: 317-325 (October 2020) 10.2144/btn-2020-0057

First draft submitted: 27 April 2020; Accepted for publication: 16 July 2020; Published online: 20 August 2020

\section{ABSTRACT}

PCR has become one of the most valuable techniques currently used in bioscience, diagnostics and forensic science. Here we review the history of PCR development and the technologies that have evolved from the original PCR method. Currently, there are two main areas of PCR utilization in bioscience: high-throughput PCR systems and microfluidics-based PCR devices for point-of-care (POC) applications. We also discuss the commercialization of these techniques and conclude with a look into their modifications and use in innovative areas of biomedicine. For example, real-time reverse transcription PCR is the gold standard for SARS-CoV-2 diagnoses. It could also be used for POC applications, being a key component of the sample-to-answer system.

\section{KEYWORDS}

COVID-19 • digital PCR • microfluidics • PCR • point-of-care diagnostics • portable systems • reverse transcription PCR • RNA virus diagnoses

\section{A brief history of PCR discovery}

There are very few inventions that can compete with the importance of PCR over the past 100 years as it revolutionized biological and genetic research. Mullis noticed that the Sanger sequencing method [1] yielded weak signals while sequencing a single copy gene due to insufficient concentration of DNA. Adding a denaturation step to split each dsDNA molecule into two ssDNAs, and a reverse primer to define the total amplicon length, resulted in the amplification of the DNA copies by two [2,3]. Unfortunately, the polymerase was destroyed in each denaturation step and had to be added for each PCR cycle, making the method implementation tedious; this was resolved by an automated system called 'Baby Blue' (Figure 1A).

Utilization of polymerase from the bacteria Thermophilus aquaticus (Taq polymerase) [8], capable of surviving temperatures of $94^{\circ} \mathrm{C}$, eliminated the necessary addition of fresh polymerase. An automated time domain temperature cycler with a stationary sample was also assembled [9], with Southern blotting used to detect the PCR product [10]. Another cycler with three zones, each with a different temperature and the sample being moved between, is called the 'space-domain system' (Figure 1B). Currently, the time domain systems are more common (Figure 1C).

\section{The history of PCR application in bioscience}

Originally, PCR was developed for the detection of mutations in the HBB gene that causes sickle cell anemia. The hybridization of radioactive-labeled oligonucleotides and the subsequent restriction analysis were used in this project to search for such inherited mutations. Therefore, the sequences of the $\beta$-globin gene were selected as the first for enzymatic amplification [3,11].

The knowledge gained during this work on the HBB gene [12] was utilized in the analysis of alleles of $H L A-D Q$ (Figure 1D) and resulted in the development of a genotyping method for this multiallelic locus using the hybridization of amplicons with allele-specific oligonucleotides [13]. The technique was applied in transplantology and forensic science. Numerous clinical applications of PCR followed especially in the field of clinical genetics [14,15] and in microbiology for the detection of viral and bacterial infections [16-18]. The usefulness of PCR as a tool for infectious disease diagnosis was first demonstrated in detection [19] in 1987 and further elaborated in later years $[20,21]$.

The finding that amplicons of different lengths determined by different primer pairs might be produced simultaneously in one PCR tube represented an important milestone in the development of PCR diagnostic approaches. This is the so-called multiplex PCR, which was used during early PCR development for the detection of deletions in DMD - one of the largest human genes (Figure 1E) [5]. This gene is localized on the X-chromosome and its mutations are responsible for Duchenne-Becker muscular dystrophy in males. Until recently, numerous diagnostic approaches were based on this principle, such as the simultaneous detection of F2 polymorphism and 


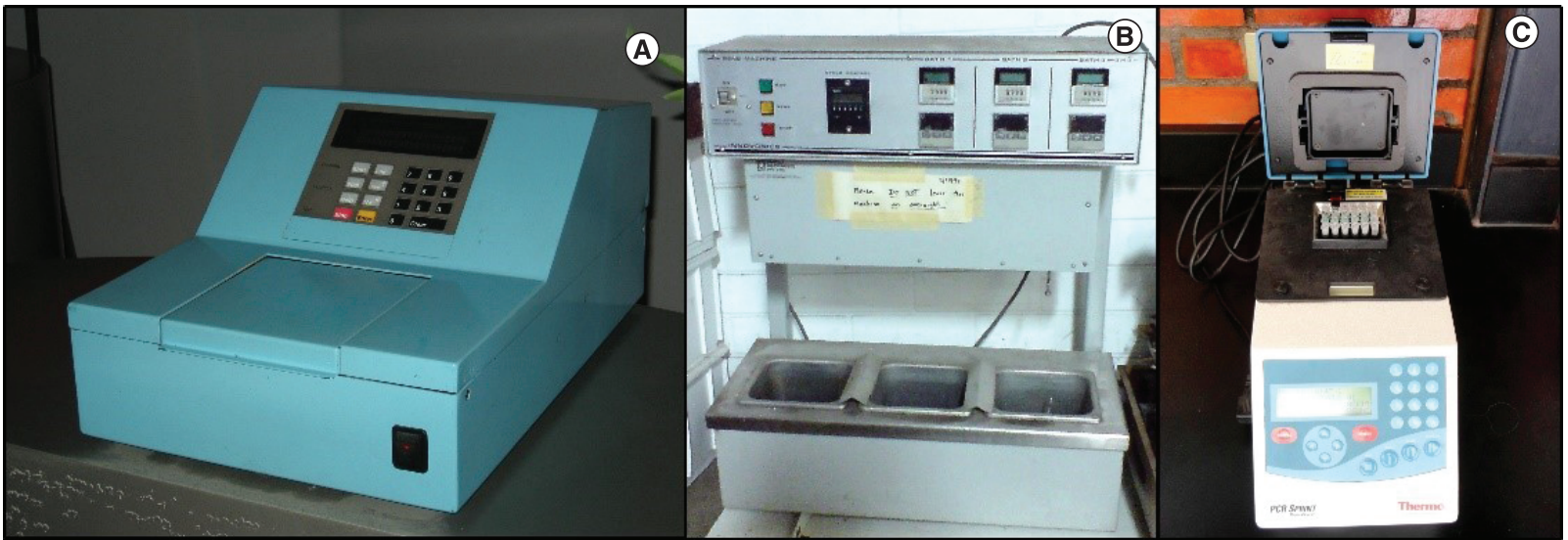

(D) PCR-allele (sequence)-specific oligonucleotide (ASO/SSO) hybridisation

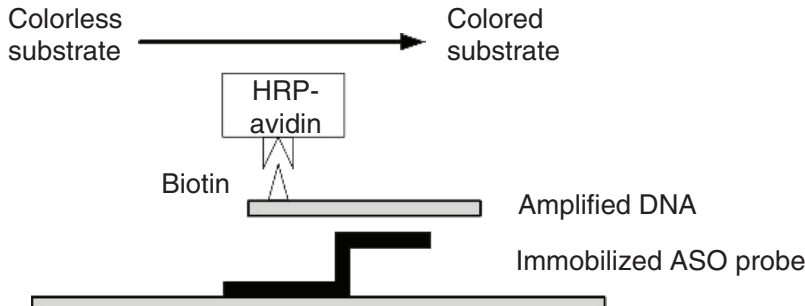

Immobilized oligonucleotide probe detection of biotin-labelled amplified DNA

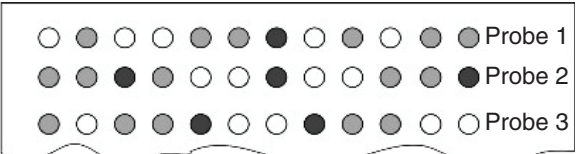

(F)

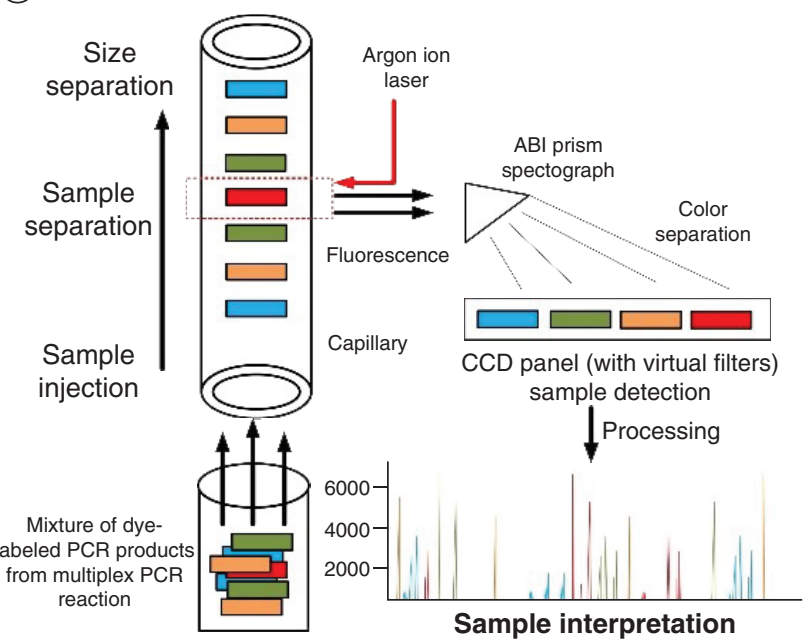

(E) Family (DRL) \# (a)
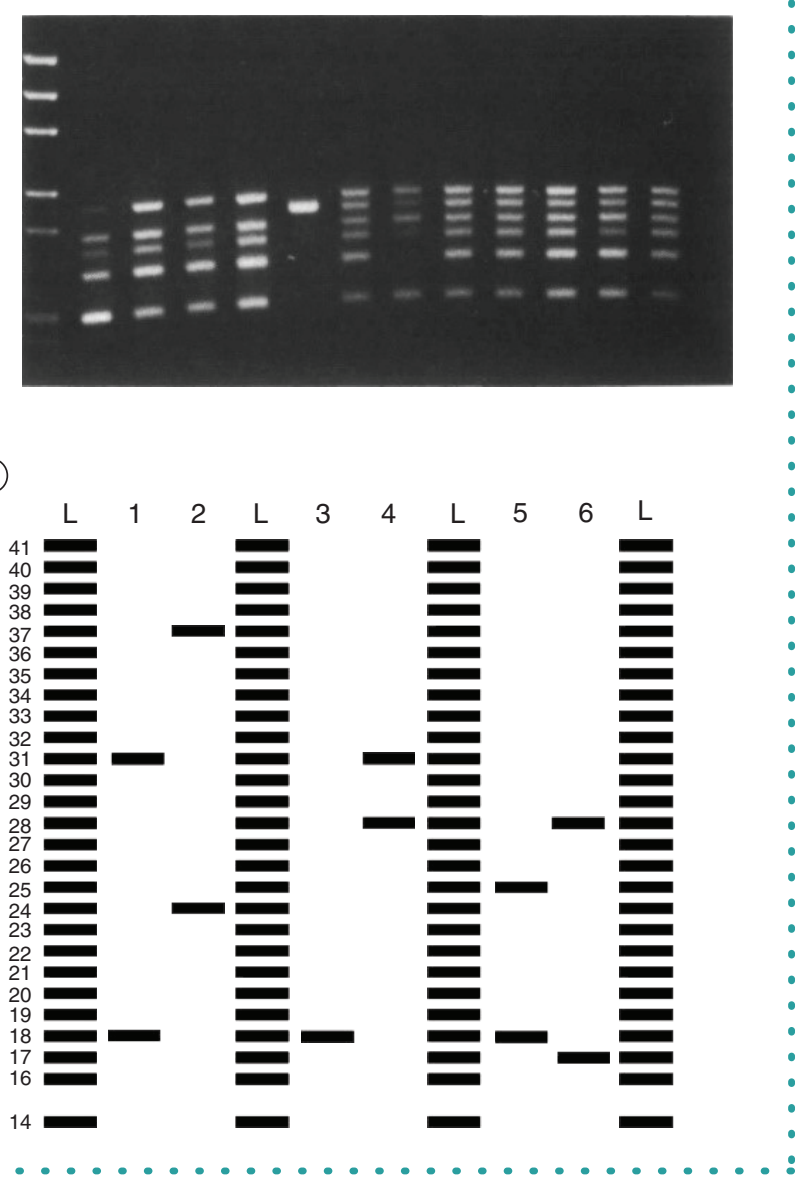

Figure 1. The development of the PCR system and its applications. (A) A prototype PCR thermal cycler developed by Cetus Corporation in 1986, which is the first model embedding the software cycling controller in the thermal cycling block. (B) Space-domain PCR. (C) Time-domain PCR. (D) Use of anchored allele-specific probes and labeled primers for the colorimetric detection of mutations in the HBB gene. (E) One of the first applications of multiplex PCR, the detection of deletions in the DMD gene in patients affected by Duchenne muscular dystrophy. (F) A recent version of the multiplex PCR with fluorescent-labeled primers and separation of amplicons using capillary electrophoresis currently used in routine forensic analysis. (G) The use of PCR for the amplification of alleles of a multiallelic minisatellite locus, silver staining of amplicons in a polyacrylamide gel, and the comparison of their lengths with an allele marker, a ladder.

Reproduced with permission from [4-7]. 
the F5 Leiden mutation [22]. Recently, the preparation of libraries of large gene panels for next-generation sequencing (NGS) has also been based on highly multiplexed PCR $[23,24]$.

After the publication of the pioneer study in which amplification of DNA from single sperm cells was demonstrated [25], a new area of PCR applications began. This pioneering development led to the recent broad uses of PCR in forensic science and assisted reproduction, where the analysis of genetic material from one or a few cells is required.

PCR entered the field of forensic science when researchers successfully demonstrated the multiplexing of six highly polymorphic minisatellite loci in one PCR tube [26]. This success came with high reproducibility of results obtained from nanogram quantities of human DNA. Further elaboration of these principles led to the introduction of multiplexed microsatellite analysis, silver staining of amplicons in a polyacrylamide gel and the comparison of their lengths with an allele marker, a ladder (Figure 1G) [27]. This was followed by the separation of fluorescent-labeled amplicons by capillary electrophoresis. This development allowed scientists to work with shorter amplicon lengths and analyze the highly degraded material [28]. This methodology currently represents the basic workflow in forensic laboratories (Figure 1F) [6].

Since 1993, following the development of a method for monitoring PCR kinetics in real time [29], PCR techniques became fully quantitative (qPCR). The incorporation of reverse transcription (RT) as the first step before thermal cycling allowed the use of PCR technologies (RT-PCR or qRT-PCR) in RNA studies [30,31]. These modifications of the basic PCR technique quickly became the gold standard for quantitative analysis of nucleic acids [32]. Until now, we had three basic systems: end-point PCR, qPCR and digital PCR (dPCR) (Figure 2A) [33]. However, there are many other variants of basic PCR techniques, one of which is bridge PCR (Figure 2B) [34].

\section{PCR miniaturization history based on a microfluidic platform}

The implementation of microfluidic systems led to the development of an entirely new family of devices, such as flow-through miniaturized and fast PCR, first using a space-domain system as seen in the very early cyclers [35]. Researchers involved in silicon micromachining quickly took up this challenge, developing miniaturized [36] and portable end point PCR and then qPCR devices.

\section{Droplet-based systems}

There are several techniques that split samples to form droplets (Figure 2C) [37]. The droplets, including cells, are loaded into the microfluidic channel and transferred to different positions within the chip, then subjected to a series of procedures such as cell lysis, DNA extraction and purification, PCR and fluorescence detection. The droplets with extracted DNA, in a small volume of a few nanoliters, are separated by an immiscible liquid, such as mineral oil, forming an emulsion. Then the thermal cycling is conducted by heating this emulsion and cameras capture the subsequent fluorescence [38]. This platform is commonly used in single-cell studies, often termed 'single-cell PCR' [39].

\section{Chip-based systems}

A variety of chip structures are fabricated by micromachining with different wells or microfluidic channels in materials such as silicon, glass or polymers, typically polydimethylsiloxane or polymethylmethacrylate. Samples are loaded into either wells or channels for subsequent DNA amplification by PCR [40]. Miniaturized PCR systems provide portability and save time. The total reaction time depends on a series of parameters such as chip size, PCR master mix volume, the thermal conductivity of the substrate and the temperature cycling rate. Researchers successfully shortened the reaction time and demonstrated an extremely fast PCR with $0.4 \mathrm{~s} / \mathrm{cycle}$, resulting in total reaction time in less than $15 \mathrm{~s}$ [41].

\section{Hybrid systems}

Alternatively, the PCR master mix is dispensed in a stationary place such as a hydrophobic/oleophobic glass coverslip and covered by mineral oil, forming a virtual reaction chamber [42] using a donut-shaped micro heater to conduct the thermal cycling beneath the virtual reaction chamber and utilizing a passive cooling method. This heating/cooling system integrated with a fluorescence optical detection method was a core of the smallest qPCR performing an amplification of cDNA from H7N9 avian influenza virus [43] and RT-PCR of Ebola virus RNA [44].

\section{Technologies that evolved from \& were inspired by PCR Digital PCR}

Many technologies have evolved from original PCR; one example is dPCR [45], which is based on splitting a PCR sample into thousands, in some cases millions, of subsamples from the original to digitize the pool of DNA molecules having either a single or no copy in each subsample. APCR is always based on microfluidics and it is either droplet based or chip based. dPCR is capable of determining the absolute quantification of the DNA/RNA copy number, avoiding time-consuming quantification by qPCR based on standard curves. It also allows multiplex PCR to amplify the number of copies of DNA samples with unfavorable ratios between abundant and rare DNAs. 


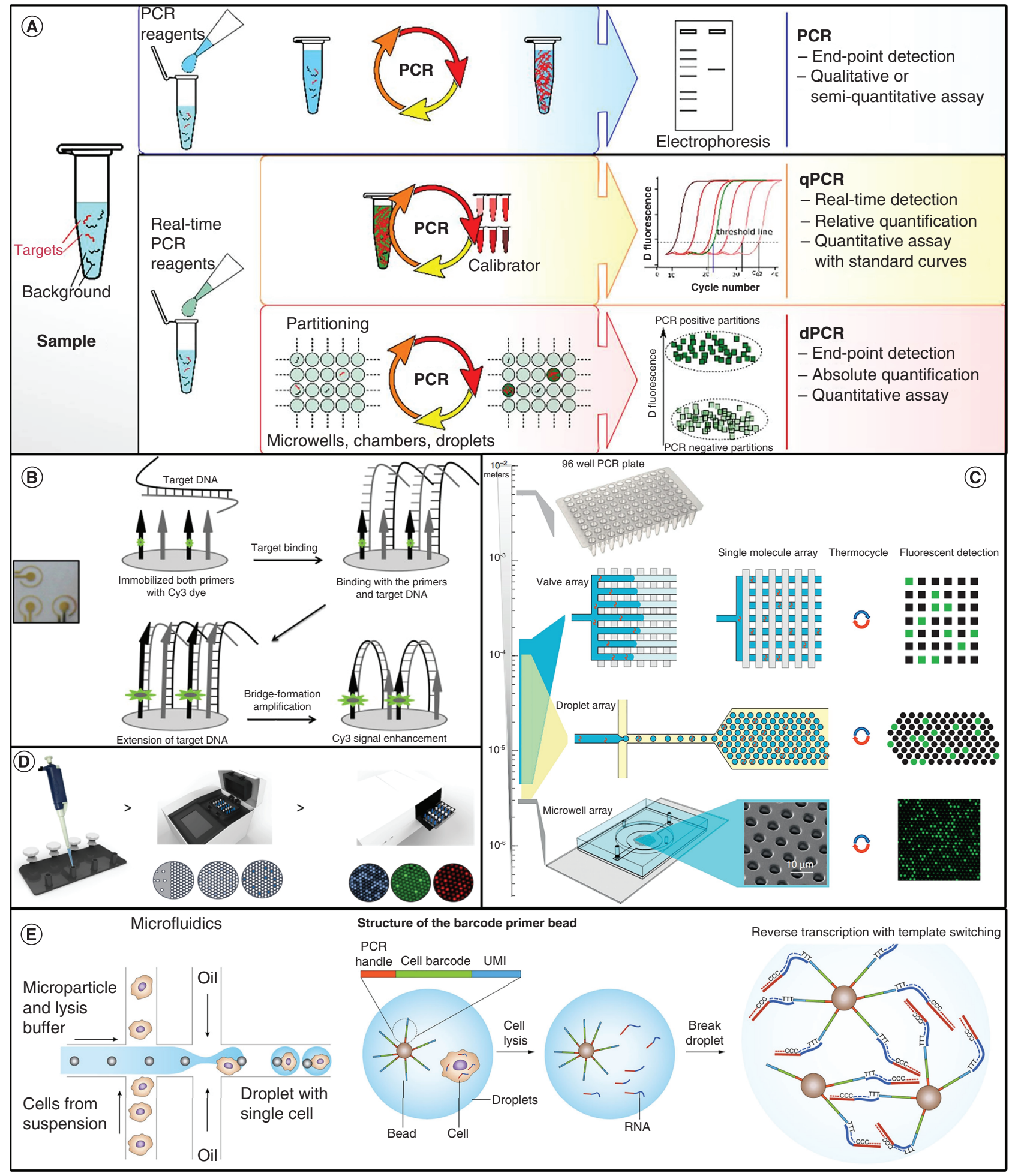

Figure 2. Current examples of commercially available techniques: quantitative PCR, droplet-based digital PCR, crystal digital PCR (cdPCR), PCR, bridge PCR for next-generation sequencing and sequencing of mRNA from individual cells using microfluidics. (A) A comparison of end-point PCR, qPCR and ddPCR. (B) Schematic representation of the principle of solid phase bridge DNA amplification. (C) Different techniques for splitting of samples. (D) Crystal droplet PCR - formation of droplet crystals. (E) PCR and droplet-based library generation for single-cell RNA sequencing. ddPCR: Droplet-based digital PCR; qPCR: Quantitative PCR.

(A) Reproduced with permission from [33]. (B) Reproduced with permission from [34], C Elsevier BV (2014). 


\section{Droplet-based digital PCR (ddPCR)}

The sample passes through the microfluidic chip forming a type of segmented flow, where the sample is split into tens of thousands of droplets separated by an immiscible liquid, such as mineral oil forming an emulsion [10]. The emulsion is collected in a vial, PCR is performed and the sample is subsequently processed by flow cytometer to count the number of droplets with positive PCR. Alternatively, the emulsion is fed into a plastic chip forming a single layer of droplets. The thermal cycling is conducted and a fluorescent image of the droplets is captured and evaluated (Figure 2D) [46]. Compared with qPCR, ddPCR has the advantages of higher precision and a lower coefficient of variation in absolute quantification [47]. The PCR multiplexing is typically conducted by probe-based fluorescence with different excitation colors for each DNA/RNA. It is also used to generate libraries for single-cell RNA sequencing (Figure 2E) [39].

\section{Chip-based digital PCR (CdPCR)}

The sample is loaded into silicon chips with wells made by a micromachining technique. Then the thermal cycling is performed and the chip is imaged by fluorescence microscopy [48] to determine the number of wells with positive PCR results [49]. Multiplexing is also performed in the same way as in ddPCR [50]. The silicon-based microfabrication allows the combination of cdPCR integrated with a heater/sensor using an ion-sensitive field-effect transistor in each well to monitor the PCR, eliminating the need for a separate fluorescence imaging system [51].

\section{Isothermal amplification}

qPCR is conducted by thermal cycling and its rate is typically limited by sample cooling, which slows with increased sample volumes. The commercial utilization of PCR was limited for several years by patent protection granted to Cetus Corporation (later sold to Chiron Corporation; CA, USA). Researchers tried to overcome problems related to cooling and bypassing the patent protection by creating new nucleic acid amplification methods. The isothermal amplification overcomes the cooling problems because it requires no cooling process. Several techniques were developed with isothermal amplification, such as loop-mediated isothermal amplification (LAMP) [52] and recombinase polymerase amplification [53], which are currently popular. Isothermal nucleic acid amplification requires no temperature cycling and has an advantage of simpler device design with lower power consumption in comparison with fast PCR. LAMP achieves high specificity by using up to six primers to identify up to eight DNA sequences of the target. The introduction of different isothermal amplification techniques also led to the development of new approaches for visualization of amplification products and for monitoring reaction kinetics independently of exonuclease activity of DNA polymerase that is employed in qPCR with TaqMan probes. The systems involving clusters of regularly interspaced short palindromic repeats (CRISPR), with a CRISPR-associated protein known as CAS, for the detection of isothermal amplification products were developed [54,55] and used also for the detection of variant sequences in amplicons obtained by PCR [56].

\section{PCR for other applications}

There are modern techniques where PCR is indispensable and some examples are platforms for NGS [57]. The Illumina platform uses the modified PCR to prepare clusters of single-molecule DNA templates each containing approximately 1000 DNA copies [58]. The lon Torrent technology detects the protons released as nucleotides are incorporated during new DNA strand synthesis. The DNA fragments for sequencing on this platform are linked with specific adapters and then amplified by emulsion PCR on the surface of 3-micron-diameter beads [59].

\section{Outstanding challenges in PCR}

Despite the great diagnostic potential of PCR, the success of each of its practical applications is highly dependent on the quality of samples containing nucleic acids for amplification. The spectrum of different inhibitors of PCR complicating the work in real-world samples, such as false-negative results or higher limits of detection, have been characterized [60]. Procedures leading to sufficient purification of samples [61,62] and to the development of inhibition-resistant DNA polymerases [63] have been developed. It has been documented that $\mathrm{APCR}$ is more resistant to the presence of inhibitors [60].

Additionally, the successful PCR amplification of GC-rich DNA sequences represent another challenge. It is complicated by the generation of secondary structures hindering full denaturation and primer annealing and represents multiple techniques to overcome this problem have been established [64,65].

The miniaturization of PCR devices highlighted another challenge, which should be solved preanalytically to achieve sensitivity comparable to established laboratories. Miniaturized devices work with low-volume samples and therefore the real-world biological samples should be effectively isolated and preconcentrated, respectively, prior to analysis with such devices.

\section{PCR commercialization: history \& success}

There are two aspects to the commercialization efforts that have made PCR a gold standard in molecular diagnostics. One is the development of an automated instrument replacing manual operations and the other is the set of reagents that increase the PCR's specificity, eliminating cross-contamination and inhibition, reducing reaction time and increasing multiplexing capability. 
The first company that took the technique into full-fledged commercialization based its technique on Cetus' original work. Later, many companies started to tackle the different aspects of the PCR system.

With the trend of miniaturization and point-of-care (POC) testing, there was also developments in PCR systems based on microfluidic platforms [42,44]. Cepheid, with their GeneXpert, created a unique system capable of performing sample-to-answer operation proven for the diagnosis of Bacillus anthraxes at US mail stations and HIV/tuberculosis in South Africa.

The most significant success of the miniaturization and utilization of microfluidics is dPCR, a technique enabled by microfluidics. Both droplet- and chip-based systems were commercialized with the number of subsamples (wells) above 1 million.

\section{Conclusion \& future perspective}

There are several techniques, such as NGS, where PCR plays an indispensable role and this role will be strengthened in the foreseeable future. PCR will play a major role in future molecular diagnostic techniques. We can envision the use of microfluidics performing parallel multiple sample analysis using handheld POC systems. The microfluidic devices will also be able to perform RT-PCR to analyze immunomagnetic exosomal RNA (Figure 3A) [40]. Droplet-based qPCR for single-cell mRNA purification and gene expression analysis will be another large application of microfluidics in the near future (Figure 3B) [38], as well as miRNA quantitation assays (Figure 3D) [66] and chip-based digital RT-PCR for absolute quantification of mRNA in single cells (Figure 3C) [50]. Currently, the parallel sequencing of all RNA or DNA molecules belonging to a single cell inside a larger cell population is possible due to emulsion PCR (Figure 2E), where the nucleic acids from each cell are enclosed in one droplet, barcoded and then amplified [39]. The only sequencing platform that bypasses PCR is the Oxford Nanopore system [67].

We also predict that paper-based systems for PCR or LAMP will be in high demand for molecular diagnostics (Figure 3E) [70]. Forensic science will be routinely conducted on location at crime scenes performing DNA profiling on a chip (Figure 3F) [71]. Detection systems are already commercially available, such as BioFire for the detection of bacteria and viruses on a chip.

Further, commercial products of such detection systems are already available, even though not many, such as BioFire, exist for the detection of bacteria and viruses on a chip (Figure 3G) [69]. We predict that more microfluidic PCR-based systems will be developed and commercialized.

The miniaturization of PCR will continue with the development of new systems integrating sample preparation with the qPCR, moving toward truly portable sample-to-answer systems for POC applications. The COVID pandemic sped up this development, causing a boom in POC systems by converting existing devices such as LAMP-based ID NOW originally developed for influenza into a SARS-CoV-2 diagnostic tool by changing primers [72,73]. There will likely be more POC devices developed for SARS-CoV-2 and later converted into diagnostics for other RNA viruses. As of 26 May 2020, there are 81 kits and systems approved by the US FDA under 'emergency use authorizations', with most based on molecular biology, typically using real-time RT-PCR [74]. Further elaboration of CRISPR-based methods $[55,56]$ to detect and differentiate amplification products can be expected, as this methodology has successfully been applied in various fields of biology.

The diagnoses systems could eventually be linked together forming an 'internet of things', as demonstrated in PCR previously. The new systems could be standalone or based on a smart phone with an Android operating system [75]. It has an advantage that the camera can be either controlled externally or internally and it can communicate with the temperature and illumination control via Bluetooth. Once the image is captured, the Android system could process it and send it to a control center via a wireless network [76]. There are portable systems besides PCR that might be used; other DNA multiplication techniques, such as LAMP and recombinase polymerase amplification are more energy efficient than PCR.

We can also envision portable dPCR systems with fast turnaround for clinical diagnostics [77], forensic science [71,78] and environmental research, avoiding time-consuming sample transfer to large facilities that risks sample degradation.

\section{Author contributions}

$\mathrm{H}$ Zhu wrote parts related to isothermal amplification and prepared the figures. $\mathrm{H}$ Zhang wrote parts related to PCR miniaturization and digital PCR. Y Xu came up with the original idea of the review and wrote the commercialization part. S Laššáková wrote parts related to applications in medicine. M Korabečná participated in the review concept and focused on historical and recent applications. P Neužil participated in the review concept and wrote the description of the PCR technique and problems with miniaturization.

\section{Financial \& competing interests disclosure}

The authors wish to acknowledge the financial support of a W099109 grant from PR China, as well as GACR project no. GA16-11140S from the Czech Republic. This study was funded by grant no. LTACH19005 from the Ministry of Education, Youth and Sport of the Czech Republic, as well as by the 2018 YFE010900 project from the Ministry of Science and Technology, PR China. The authors have no other relevant affiliations or financial involvement with any organization or entity with a financial interest in or financial conflict with the subject matter or materials discussed in the manuscript apart from those disclosed.

No writing assistance was utilized in the production of this manuscript. 


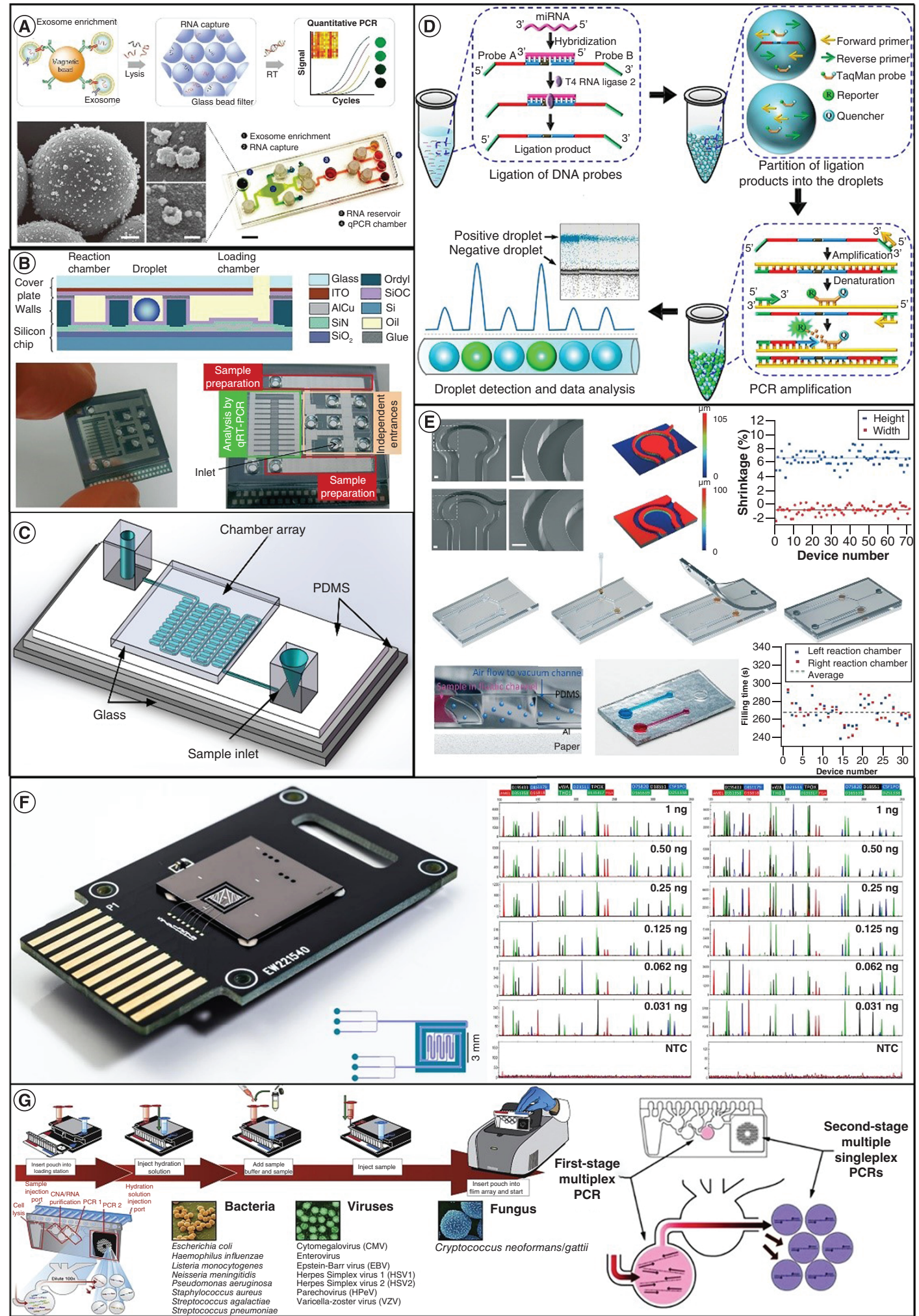

Figure 3. Applications of microfluidics into massively parallel and handheld point-of-care systems. (A) Chip-based integrated real-time reverse transcription PCR platform for the analysis of the immunomagnetic exosomal RNA. (B) Droplet-based quantitative PCR for a single cell to mRNA purification and gene expression analysis. (C) Chip-based digital RT-PCR for absolutequantification of mRNA in single cells. (D) Droplet-based dPCR for miRNA quantitation assay. (E) Paper-based LAMP system made by polydimethylsiloxane for molecular diagnostics. (F) Forensic science, DNA profiles on a chip. (G) BioFire, detection of bacteria and viruses on a chip.

Reproduced with permission from $[38,50,68,69]$. 


\section{Open access}

This work is licensed under the Attribution-NonCommercial-NoDerivatives 4.0 Unported License. To view a copy of this license, visit http: //creativecommons.org/licenses/by-nc-nd/4.0/

\section{References}

Papers of special note have been highlighted as: $\bullet$ of interest; $\bullet \bullet$ of considerable interest

1. Sanger F, Nicklen S, Coulson AR. DNA sequencing with chain-terminating inhibitors. Proc. Natl Acad. Sci. USA 74(12), 5463-5467 (1977).

2. Mullis K, Faloona F, Scharf S, Saiki R, Horn G, Erlich H. Specific enzymatic amplification of DNA in vitro: the polymerase chain reaction. Cold Spring Harb. Symp. Quant. Biol. 51(Pt. 1), 263-273 (1986)

.. The first description of PCR appeared after the patent application written in 1985 (patent approved in July 1987).

3. Saiki RK, Scharf S, Faloona F et al. Enzymatic amplification of beta-globin genomic sequences and restriction site analysis for diagnosis of sickle-cell anemia. Science 230(4732), 13501354 (1985).

4. Hurd C, Cavanagh G, Schuh A, Ouwehand W, Metcalfe P. Genotyping for platelet-specific antigens: techniques for the detection of single nucleotide polymorphisms. Vox Sang. 83(1), 1-12 (2002).

5. Chamberlain JS, Gibbs RA, Rainer JE, Nguyen PN, Thomas C. Deletion screening of the Duchenne muscular dystrophy locus via multiplex DNA amplification. Nucleic Acids Res. 16(23), 11141-11156 (1988).

6. Butler JM, Buel E, Crivellente F, McCord BR. Forensic DNA typing by capillary electrophoresis using the ABI Prism 310 and 3100 genetic analyzers for STR analysis. Electrophoresis 25 (1011), 1397-1412 (2004).

7. Kloosterman AD, Budowle B, Daselaar P. PCR-amplification and detection of the human D1S80 VNTR locus. Int. J. Legal Med. 105(5), 257-264 (1993)

8. Saiki RK, Gelfand DH, Stoffel S et al. Primer-directed enzymatic amplification of DNA with a thermostable DNA polymerase. Science 239(4839), 487-491 (1988).

.. The thermostable DNA polymerase was introduced to facilitate the PCR process.

9. Bartlett JM, Stirling D. A short history of the polymerase chain reaction. In: PCR Protocols. Bartlett JMS, Stirling D (Eds). Humana Press, NY, USA, 3-6, Methods in Molecular Biology, Vol. 226. (2003).

10. Schiffman M, Bauer H, Lorincz A et al. Comparison of Southern blot hybridization and polymerase chain reaction methods for the detection of human papillomavirus DNA. J. Clin. Microbiol. 29(3), 573-577 (1991).

11. Embury SH, Scharf SJ, Saiki RK et al. Rapid prenatal diagnosis of sickle cell anemia by a new method of DNA analysis. N. Engl. J. Med. 316(11), 656-661 (1987).

12. Saiki RK, Bugawan TL, Horn GT, Mullis KB, Erlich HA. Analysis of enzymatically amplified $\beta$-globin and HLA-DQ $\alpha$ DNA with allele-specific oligonucleotide probes. Nature 324(6093), 163-166 (1986).

13. Saiki RK, Chang C-A, Levenson $\mathrm{CH}$ et al. Diagnosis of sickle cell anemia and $\beta$-thalassemia with enzymatically amplified DNA and nonradioactive allele-specific oligonucleotide probes. N. Engl. J. Med. 319(9), 537-541 (1988).

14. Lebo RV, Saiki RK, Swanson K, Montano MA, Erlich HA, Golbus MS. Prenatal diagnosis of alpha-thalassemia by polymerase chain reaction and dual restriction enzyme analysis. Hum. Genet. 85(3), 293-299 (1990)

15. Beggs AH, Koenig M, Boyce FM, Kunkel LM. Detection of $98 \%$ of DMD/BMD gene deletions by polymerase chain reaction. Hum. Genet. 86(1), 45-48 (1990).

16. Cassol SA, Poon MC, Pal R et al. Primer-mediated enzymatic amplification of cytomegalovirus (CMV) DNA. Application to the early diagnosis of CMV infection in marrow transplant recipients. J. Clin. Invest. 83(4), 1109-1115 (1989).

17. Olive DM. Detection of enterotoxigenic Escherichia coli after polymerase chain reaction amplification with a thermostable DNA polymerase. J. Clin. Microbiol. 27(2), 261-265 (1989).

18. Zeldis JB, Lee JH, Mamish D et al. Direct method for detecting small quantities of hepatitis B virus DNA in serum and plasma using the polymerase chain reaction. J. Clin. Invest. 84(5), 1503-1508 (1989)

19. Kwok S, Mack DH, Mullis KB et al. Identification of human immunodeficiency virus sequences by using in vitro enzymatic amplification and oligomer cleavage detection. J. Virol. 61 (5), 1690-1694 (1987).

20. Ou CY, Kwok S, Mitchell SW et al. DNA amplification for direct detection of HIV-1 in DNA of peripheral blood mononuclear cells. Science 239(4837), 295-297 (1988).

21. Wormser GP, Joline C, Bittker S, Forseter G, Kwok S, Sninsky JJ. Polymerase chain reaction for seronegative health care workers with parenteral exposure to HIV-infected patients. N. Engl. J. Med. 321(24), 1681-1682 (1989).

22. Mellars G, Jenkins PV, Perry DJ. Multiplex PCR for detection of the prothrombin $3^{\prime}$-UTR (G20210A) polymorphism and the factor V leiden mutation. In: Hemostasis and Thrombosis Protocols. Pasi KJ, Perry DJ (Eds). Humana Press, NY, USA, 287-289, Methods in Molecular Biology, Vol. 31 (1999).

23. Stahlberg A, Krzyzanowski PM, Egyud M, Filges S, Stein L, Godfrey TE. Simple multiplexed PCR-based barcoding of DNA for ultrasensitive mutation detection by next-generation sequencing. Nat. Protoc. 12(4), 664-682 (2017).

24. Hickman MP, Grisedale KS, Bintz BJ et al. Recovery of whole mitochondrial genome from compromised samples via multiplex PCR and massively parallel sequencing. Future Sci. OA 4(9), FSO336 (2018).

25. Boehnke M, Arnheim N, Li H, Collins FS. Fine-structure genetic mapping of human chromosomes using the polymerase chain reaction on single sperm: experimental design considerations. Am. J. Hum. Genet. 45(1), 21-32 (1989).

26. Jeffreys AJ, Wilson V, Neumann R, Keyte J. Amplification of human minisatellites by the polymerase chain reaction: towards DNA fingerprinting of single cells. Nucleic Acids Res. 16(23), 10953-10971 (1988)

27. Encyclopedia of Forensic Sciences (2nd Edition). Siegel JA, Saukko PJ, Houck MM (Eds). Academic Press, MA, USA (2013).

28. Ladas I, Yu F, Leong KW et al. Enhanced detection of microsatellite instability using pre-PCR elimination of wild-type DNA homo-polymers in tissue and liquid biopsies. Nucleic Acids Res. 46(12), e74 (2018).

29. Higuchi R, Fockler C, Dollinger G, Watson R. Kinetic PCR analysis: real-time monitoring of DNA amplification reactions. Biotechnology 11(9), 1026-1030 (1993)

.. The methodological approach for quantification of PCR products in real time was introduced in this publication.

30. Becker-Andre M, Hahlbrock K. Absolute mRNA quantification using the polymerase chain reaction (PCR). A novel approach by a PCR aided transcript titration assay (PATTY). Nucleic Acids Res. 17(22), 9437-9446 (1989)

31. Chelly J, Kaplan JC, Maire P, Gautron S, Kahn A. Transcription of the dystrophin gene in human muscle and non-muscle tissue. Nature 333(6176), 858-860 (1988).

32. Bustin SA, Benes V, Garson JA et al. The MIQE guidelines: minimum information for publication of quantitative real-time PCR experiments. Clin. Chem. 55(4), 611-622 (2009).

33. Quan P-L, Sauzade M, Brouzes E. dPCR: a technology review. Sensors 18(4), 1271 (2018).

34. Shin Y, Kim J, Lee TY. A solid phase-bridge based DNA amplification technique with fluorescence signal enhancement for detection of cancer biomarkers. Sensor Actuat. B-Chem. 199, 220-225 (2014).

35. Kopp MU, de Mello AJ, Manz A. Chemical amplification: continuous-flow PCR on a chip. Science 280(5366), 1046-1048 (1998)

36. Northrup MA, Ching MT, White RM, Watson RT. DNA amplification with a microfabricated reaction chamber. Presented at: Transducer '93: the 7th International Conference on Solid-State Sensors and Actuators. Yokohama, Japan, 7-10 June 1993.

37. Streets AM, Huang Y. Microfluidics for biological measurements with single-molecule resolution. Curr. Opin. Biotech. 25, 69-77 (2014).

38. Rival A, Jary D, Delattre C et al. An EWOD-based microfluidic chip for single-cell isolation, mRNA purification and subsequent multiplex qPCR. Lab Chip 14(19), 3739-3749 (2014).

39. Hwang B, Lee JH, Bang D. Single-cell RNA sequencing technologies and bioinformatics pipelines. Exp. Mol. Med. 50 (8), 96 (2018).

40. Shao H, Chung J, Lee $\mathrm{K}$ et al. Chip-based analysis of exosomal mRNA mediating drug resistance in glioblastoma. Nat. Commun. 6, 6999 (2015).

41. Farrar JS, Wittwer CT. Extreme PCR: efficient and specific DNA amplification in 15-60 seconds. Clin. Chem. 61(1), 145 (2015).

- The fastest real-time PCR so far was demonstrated in this publication.

42. Neuzil P, Pipper J, Hsieh TM. Disposable real-time microPCR device: lab-on-a-chip at a low cost. Mol. Biosyst. 2(6-7), 292-298 (2006). 
43. Ahrberg CD, Ilic BR, Manz A, Neužil P. Handheld real-time PCR device. Lab Chip 16(3), 586-592 (2016).

- The smallest real-time PCR to date was introduced in this publication.

44. Ahrberg CD, Manz A, Neuźil P. Palm-sized device for point-of-care Ebola detection. Anal. Chem. 88(9), 4803-4807 (2016).

45. Vogelstein B, Kinzler KW. Digital PCR. Proc. Natl Acad. Sci. USA 96(16), 9236-9241 (1999).

-. The first digital PCR was demonstrated.

46. Madic J, Zocevic A, Senlis V et al. Three-color crystal digital PCR. Biomol. Detect. Quant. 10, 34-46 (2016).

47. Hindson CM, Chevillet JR, Briggs HA et al. Absolute quantification by droplet digital PCR versus analog real-time PCR. Nat. Methods 10, 1003 (2013).

48. Li H, Zhang H, Xu Y et al. Versatile digital polymerase chain reaction chip design, fabrication and image processing. Sens. Actuators B Chem. 283, 677-684 (2019).

49. Zhu Q, Xu Y, Qiu L et al. A scalable self-priming fractal branching microchannel net chip for digital PCR. Lab Chip 17(9), 1655-1665 (2017).

50. Thompson AM, Gansen A, Paguirigan AL, Kreutz JE, Radich JP, Chiu DT. Self-digitization microfluidic chip for absolute quantification of mRNA in single cells. Anal. Chem. 86(24), 1230812314 (2014).

51. Guiducci C, Spiga FM. Another transistor-based revolution: on-chip qPCR. Nat. Methods 10, 617 (2013).

52. Notomi T, Okayama H, Masubuchi $\mathrm{H}$ et al. Loop-mediated isothermal amplification of DNA. Nucleic Acids Res. 28(12), E63 (2000).

53. Toldra A, Jauset-Rubio M, Andree KB et al. Detection and quantification of the toxic marine microalgae Karlodinium veneficum and Karlodinium armiger using recombinase polymerase amplification and enzyme-linked oligonucleotide assay. Anal. Chim. Acta 1039, 140-148 (2018).

54. Zhou W, Hu L, Ying L, Zhao Z, Chu PK, Yu X-F. A CRISPR-Cas9-triggered strand displacement amplification method for ultrasensitive DNA detection. Nat. Commun. 9(1), 1-11 (2018).

55. Kellner MJ, Koob JG, Gootenberg JS, Abudayyeh 00, Zhang F. SHERLOCK: nucleic acid detection with CRISPR nucleases. Nat. Protoc. 14(10), 2986-3012 (2019).

- The method using clusters of regularly interspaced short palindromic repeats nucleases for nucleic acid detection is described.

56. Wang Q, Zhang B, Xu X, Long F, Wang J. CRISPR-typing PCR (ctPCR), a new Cas9-based DNA detection method. Sci. Rep. 8(1), 1-13 (2018).

57. Metzker ML. Sequencing technologies-the next generation. Nat. Rev. Genet. 11(1), 31-46 (2009).

58. Voelkerding KV, Dames SA, Durtschi JD. Next-generation sequencing: from basic research to diagnostics. Clin. Chem. 55(4), 641-658 (2009).

59. Quail MA, Smith M, Coupland $P$ et al. A tale of three next generation sequencing platforms: comparison of lon Torrent, Pacific Biosciences and Illumina MiSeq sequencers. BMC Genom. 13(1), 341 (2012).

60. Sidstedt M, Rådström P, Hedman J. PCR inhibition in qPCR, dPCR and MPS - mechanisms and solutions. Anal. Bioanal. Chem. 412, 2009-2023 (2020).

61. Das A, Spackman E, Pantin-Jackwood MJ, Suarez DL. Removal of real-time reverse transcription polymerase chain reaction (RT-PCR) inhibitors associated with cloacal swab samples and tissues for improved diagnosis of Avian influenza virus by RT-PCR. J. Vet. Diagn. Invest. 21(6), $771-778$ (2009).

62. Hu Q, Liu Y, Yi S, Huang D. A comparison of four methods for PCR inhibitor removal. Forensic Sci. Int. Genet. 16, 94-97 (2015).

63. Kermekchiev MB, Kirilova LI, Vail EE, Barnes WM. Mutants of Taq DNA polymerase resistant to PCR inhibitors allow DNA amplification from whole blood and crude soil samples. Nucleic Acids Res. 37(5), e40-e40 (2009)

64. Strien J, Sanft J, Mall G. Enhancement of PCR amplification of moderate GC-containing and highly GC-rich DNA sequences. Mol. Biotechnol. 54(3), 1048-1054 (2013).

65. Green MR, Sambrook J. Polymerase chain reaction (PCR) amplification of GC-rich templates. Cold Spring Harb. Protoc. 2019(2), pdb. prot095141 (2019).

66. Ahrberg CD, Manz A, Neuzil P. Palm-sized device for point-of-care ebola detection. Anal. Chem. 88(9), 4803-4807 (2016).

67. Jain M, Olsen HE, Paten B, Akeson M. The Oxford Nanopore MinION: delivery of nanopore sequencing to the genomics community. Genome Biol. 17(1), 239 (2016).

68. Tian H, Sun Y, Liu C, Duan X, Tang W, Li Z. Precise quantitation of microRNA in a single cell with droplet digital PCR based on ligation reaction. Anal. Chem. 88(23), 11384-11389 (2016).

69. Rhein J, Bahr NC, Hemmert AC et al. Diagnostic performance of a multiplex PCR assay for meningitis in an HIV-infected population in Uganda. Diagn. Micr. Infec. Dis. 84(3), 268-273 (2016).

70. Hiltunen J, Liedert C, Hiltunen M et al. Roll-to-roll fabrication of integrated PDMS-paper microfluidics for nucleic acid amplification. Lab Chip 18(11), 1552-1559 (2018).

71. Cornelis S, Fauvart M, Gansemans Y et al. Multiplex STR amplification sensitivity in a silicon microchip. Sci. Rep. 8(1), 9853 (2018).

72. Kanwar N, Michael J, Doran K, Montgomery E, Selvarangan R. Comparison of the ID Now influenza A \& B 2, Cobas influenza A/B and Xpert Xpress Flu point-of-care nucleic acid amplification tests for influenza A/B virus detection in children. J. Clin. Microbiol. 58(3), e01611-e01619 (2020).

73. Melchers WJ, Kuijpers J, Sickler JJ, Rahamat-Langendoen J. Lab-in-a-tube: real-time molecular point-of-care diagnostics for influenza A and B using the cobas ${ }^{\mathbb{R}}$ Liat ${ }^{\mathbb{R}}$ system. J. Med. Virol. 89(8), 1382-1386 (2017).

74. US Food and Drug Administration. Coronavirus disease 2019 (COVID-19) emergency use authorizations for medical devices. http://www.fda.gov/medical-devices/emergency-use-author izations-medical-devices/coronavirus-disease-2019-covid-19-emergency-use-authorizations-medical-devices

75. Gou T, Hu J, Wu W et al. Smartphone-based mobile digital PCR device for DNA quantitative analysis with high accuracy. Biosens. Bioelectron. 120, 144-152 (2018).

76. Zhu H, Podesva P, Liu X et al. loT PCR for pandemic disease detection and its spread monitoring. Sens. Actuators B Chem. 303,127098 (2020).

77. Sorek N, Ashkenazi S, Livni G, Ben-Zvi H. Neisseria meningitidis and cytomegalovirus simultaneous detection in the filmarray meningitis/encephalitis panel and its clinical relevance. IDCases 17, e00516 (2019).

78. Cornelis S, Tytgat O, Fauvart M et al. Silicon $\mu$ PCR chip for forensic STR profiling with HyBeacon probe melting curves. Sci. Rep. 9(1), 7341-7312 (2019). 
